\title{
Determination of formal kinetic constants of thermal decomposition of aqueous hydrogen peroxide solution in a mixture of magnetic powder, based on experimental thermogram, obtained in adiabatic conditions
}

\author{
Jamshed Zaripov $^{1, \mathrm{a}}$, Boris Borisov ${ }^{2}$, and Sergey Bondarchuk ${ }^{3}$ \\ ${ }^{1}$ Tajik Technical University, 734042 Dushanbe, Tajikistan \\ 2 Tomsk Polytechnic University, 634050 Tomsk, Russia \\ ${ }^{3}$ Tomsk State Pedagogical University, 634061 Tomsk, Russia
}

\begin{abstract}
Process of thermal decomposition of hydrogen peroxide aqueous solution with the addition of magnetic powder in the form of toner for printers and lanthanum manganite were considered. Obtained resulting from an experiment in the Dewar container conducted thermogram analyzed using mass balance equations and heat. Formal kinetic parameters determined, and conclude that the magnetic powder in the mixture does not have catalytic properties. The described technique is recommended as a rapid analysis of the kinetics of the various reactions to substances having predefined thermal and thermodynamic properties.
\end{abstract}

Recently, it has been suggested to use fluids mixed with a fine powder to change the thermophysical features of coolants in order to increase the heat exchanger efficiency. Application of magnetic powders allows for additional control over unit operation using the magnetic field. An aqueous hydrogen peroxide solution is often suggested to be used as a coolant in a variety of heat exchangers (such as solar collectors). The aqueous hydrogen peroxide solution with additives of fine magnetic powder can significantly improve the efficiency of heat exchangers. To study the kinetics of thermal decomposition of hydrogen peroxide aqueous solution with added magnetic powder, series of experiments were done to determine the process thermogram in adiabatic conditions of Dewar vessels.

Dynamic heat balance equation for the reaction of thermal decomposition of hydrogen peroxide aqueous solution, considering the presence of magnetic powder particles and the reaction of hydrogen peroxide thermal decomposition are recorded under the assumption of the process equilibrium within the entire time interval $\tau$.

During experiments the mixture temperature variations from the initial to final did not exceed $8.5 \mathrm{~K}$, which allows, according to the Hess's law, heat of reaction $\left(q_{d}, \mathrm{~J} / \mathrm{mol}\right)$ to be taken as constant. The thermodynamic system is a colloidal solution of hydrogen peroxide, oxygen in water (with current masses, respectively, $m_{\mathrm{H}_{2} \mathrm{O}_{2}}, m_{\mathrm{O}_{2}}, m_{\mathrm{H}_{2} \mathrm{O}}$ ) and fine magnetic powder, consisting of toner for printers and lanthanum manganite $\left(\mathrm{La}_{\mathrm{y}} \mathrm{SrMnO}_{3-\mathrm{X}}(y<\mathrm{x})\right)$ of the total mass $m_{m p}$. Specific heat components, respectively, $c_{\mathrm{H}_{2} \mathrm{O}_{2}}, c_{\mathrm{O}_{2}}, c_{\mathrm{H}_{2} \mathrm{O}} \& c_{m p}$ are temperature functions for a general case. Heat from the

\footnotetext{
${ }^{a}$ Corresponding author: bvborisov@tpu.ru
}

This is an Open Access article distributed under the terms of the Creative Commons Attribution License 4.0, which permits unrestricted use, distribution, and reproduction in any medium, provided the original work is properly cited. 
hydrogen peroxide decomposition reaction $Q=-q_{r} \frac{d m_{\mathrm{H}_{2} \mathrm{O}_{2}}}{d \tau}$ goes to change the system's internal energy $U: \frac{d U}{d \tau}=\left(c_{\mathrm{H}_{2} \mathrm{O}_{2}} m_{\mathrm{H}_{2} \mathrm{O}_{2}}+c_{\mathrm{O}_{2}} m_{\mathrm{O}_{2}}+c_{\mathrm{H}_{2} \mathrm{O}} m_{\mathrm{H}_{2} \mathrm{O}}+c_{m p} m_{m p}\right) \frac{d T}{d \tau}$.

In terms of the above assumptions, the heat balance equation is set down as follows:

$$
\left(c_{\mathrm{H}_{2} \mathrm{O}_{2}} m_{\mathrm{H}_{2} \mathrm{O}_{2}}+c_{\mathrm{O}_{2}} m_{\mathrm{O}_{2}}+c_{\mathrm{H}_{2} \mathrm{O}} m_{\mathrm{H}_{2} \mathrm{O}}+c_{m p} m_{m p}\right) \frac{d T}{d \tau}=-q_{r} \frac{d m_{\mathrm{H}_{2} \mathrm{O}_{2}}}{d \tau} .
$$

Mass of the system is assumed the same: $m=m_{\mathrm{H}_{2} \mathrm{O}_{2}}+m_{\mathrm{O}_{2}}+m_{\mathrm{H}_{2} \mathrm{O}}+m_{m p}$.

According to $\mathrm{H}_{2} \mathrm{O}_{2}=\mathrm{H}_{2} \mathrm{O}+\frac{1}{2} \mathrm{O}_{2}+q_{r}$ mass balance equation system is complemented by the balance equation of individual components: $-\frac{d m_{\mathrm{H}_{2} \mathrm{O}_{2}}}{d \tau}=\frac{d m_{\mathrm{H}_{2} \mathrm{O}}}{d \tau}+\frac{d m_{\mathrm{O}_{2}}}{d \tau}$.

Under the Arrhenius theory, the rate of hydrogen peroxide thermal decomposition (loss) $\mathrm{H}_{2} \mathrm{O}_{2}$ reaction is described by the following ratio:

$$
\frac{d c}{d \tau}=-c^{n} A \exp \left(-\frac{E_{a}}{R T}\right),
$$

where $c$-concentration of $\mathrm{H}_{2} \mathrm{O}_{2},[c]=\mathrm{kmol} / \mathrm{m}^{3} ; n$ - the reaction order, $E_{a}$ - activation energy $\left[E_{a}\right]=$ $\mathrm{kmol} / \mathrm{kJ} ; R$ - universal gas constant $R=8314 \mathrm{~J} /(\mathrm{kmol} \cdot \mathrm{K})$. Dewar volume $V$, and consequently, of the working fluid remains unchanged. As a result,

$$
\frac{d c}{d \tau}=\frac{1}{V \cdot M_{\mathrm{H}_{2} \mathrm{O}_{2}}} \frac{d m_{\mathrm{H}_{2} \mathrm{O}_{2}}}{d \tau} \Rightarrow \frac{d m_{\mathrm{H}_{2} \mathrm{O}_{2}}}{d \tau}=V \cdot M_{\mathrm{H}_{2} \mathrm{O}_{2}} \frac{d c}{d \tau} .
$$

From (1) with consideration for (2) and (3):

$$
\frac{d T}{d \tau}=\frac{q_{r}\left(V \cdot M_{\mathrm{H}_{2} \mathrm{O}_{2}}\right)^{1-n}}{c_{\mathrm{H}_{2} \mathrm{O}_{2}} m_{\mathrm{H}_{2} \mathrm{O}_{2}}+c_{\mathrm{O}_{2}} m_{\mathrm{O}_{2}}+c_{\mathrm{H}_{2} \mathrm{O}} m_{\mathrm{H}_{2} \mathrm{O}}+c_{m p} m_{m p}} m_{\mathrm{H}_{2} \mathrm{O}_{2}}^{n} A \exp \left(-\frac{E_{a}}{R T}\right) .
$$

Equation (4) is closed by ratios for current values of component masses:

$$
\begin{aligned}
& m_{\mathrm{H}_{2} \mathrm{O}_{2}}=\left.m_{\mathrm{H}_{2} \mathrm{O}_{2}}\right|_{\tau=0}+\int_{0}^{\tau} \frac{d m_{\mathrm{H}_{2} \mathrm{O}_{2}}}{d \tau} d \tau \\
& m_{\mathrm{H}_{2} \mathrm{O}_{2}}=\left.m_{\mathrm{H}_{2} \mathrm{O}}\right|_{\tau=0}-\frac{M_{\mathrm{H}_{2} \mathrm{O}}}{M_{\mathrm{H}_{2} \mathrm{O}_{2}}} \int_{0}^{\tau} \frac{d m_{\mathrm{H}_{2} \mathrm{O}_{2}}}{d \tau} d \tau, \\
& m_{\mathrm{O}_{2}}=-\frac{0,5 M_{\mathrm{O}_{2}}}{M_{\mathrm{H}_{2} \mathrm{O}_{2}}} \int_{0}^{\tau} \frac{d m_{\mathrm{H}_{2} \mathrm{O}_{2}}}{d \tau} d \tau
\end{aligned}
$$

where $M_{\mathrm{H}_{2} \mathrm{O}}, M_{\mathrm{H}_{2} \mathrm{O}_{2}}$ and $\mathrm{M}_{\mathrm{O}_{2}}$, respectively, the molecular masses of water, hydrogen peroxide and oxygen.

To solve the system (4) and (5) temperatures and masses of components at the initial moment of time $(\tau=0)$ are involved as the initial conditions.

Tabulated values of the specific heats of hydrogen peroxide, oxygen and water were used for the numerical implementation. Their mean values were, respectively:

$$
c_{\mathrm{H}_{2} \mathrm{O}_{2}}=2,62 \mathrm{~kJ} /(\mathrm{kg} \cdot \mathrm{K}), \quad c_{\mathrm{O}_{2}}=1,004 \mathrm{~kJ} /(\mathrm{kg} \cdot \mathrm{K}), \quad c_{\mathrm{H}_{2} \mathrm{O}}=4,18 \mathrm{~kJ} /(\mathrm{kg} \cdot \mathrm{K}) .
$$

The magnetic powder heat capacity, determined in separate independent experiments, was

$$
c_{m p}=2,925 \mathrm{~kJ} /(\mathrm{kg} \cdot \mathrm{K}) .
$$

Thermal effect of the thermal decomposition reaction $q_{r}=98 \mathrm{~kJ} / \mathrm{kmol}$ is the minimal of those mentioned in references, and that allows evaluating the upper limit for the thermal decomposition reaction rate. The experimental results processing, the equation numerical solution (4) to determine the kinetics constants of the reaction under investigation were carried out by means of MS EXEL.

Using this program, the results of experiments were smoothed, for that reason the trend lines were determined. The obtained lines were used to determine the dynamics of temperature derivatives in 
Thermophysical Basis of Energy Technologies

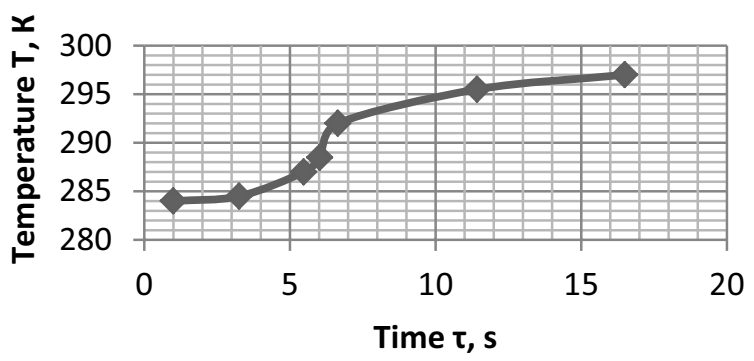

Figure 1. Example of experimental thermogram.

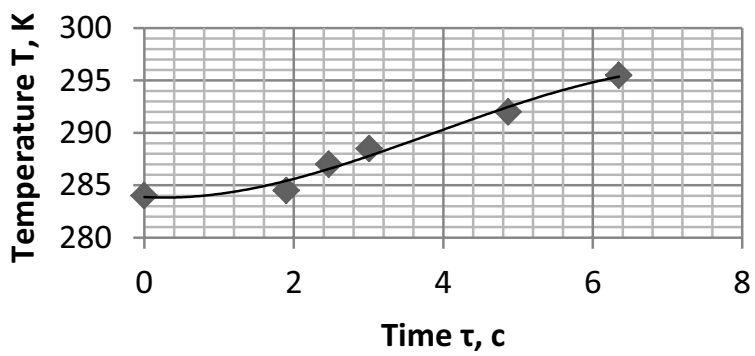

Figure 2. Example of the initial part of experimental thermogram with the printed trend line.

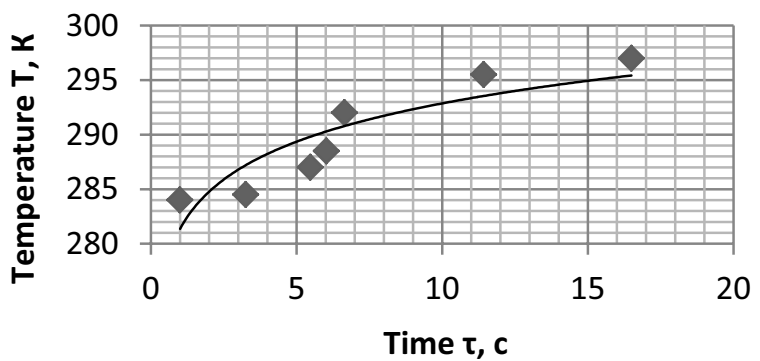

Figure 3. Example of experimental thermogram with the printed trend line.

the Dewar in time, and which values in the selected time interval served as input parameters for the regression analysis, which was used to determine the sought data on the formal kinetics constants.

Analysis of the experimental data, obtained by J.A. Zaripov, indicates that the thermal decomposition reaction of hydrogen peroxide has two periods of time, which are significantly different from each other (Fig. 1). This is noted by other authors [1-3]. For the numerical analysis of the experimental results, the best approximation of trend line for the reaction's initial period are thirddegree polynomials for cases under study (Fig. 2). Here the approximation error is not greater than $1.8 \div 2.0 \%$. Power function was the best overall trend line function for the obtained thermograms. Here the approximation error did not exceed $6.5 \div 7.0 \%$ (Fig. 3).

The regression analysis has revealed that the closest description of kinetics of thermal decomposition of hydrogen peroxide in the initial portion is a second-order response (to be exact, it is closer to the second: $n=1.8 \div 2.1$ ) with an activation energy within the range of $78 \div 87 \mathrm{MJ} / \mathrm{kmol}$. Subsequently, the reaction order reduced to zero fairly quickly (the reaction rate is practically independent of concentration) and activation energy increases to $120 \div 240 \mathrm{MJ} / \mathrm{kmol}$. Depth value of hydrogen peroxide 
decomposition for long times $(10 \div 30$ minutes) was calculated from the processed thermograms results and compared with the results of X-ray fluorescence analysis method and differential thermal analysis. A satisfactory coincidence was obtained.

The following conclusions can be made, based on the research results:

1. Magnetic powder, used for the experiments, does not possess catalytic properties for the hydrogen peroxide aqueous solution decomposition reaction, as proved by the activation energy value, obtained from the experimental thermograms processing and close to the value of $73 \mathrm{MJ} / \mathrm{kmol}$, which corresponds to the reaction without a catalyst, according to data. For example, [2, 3];

2. The estimated time of decomposition of the hydrogen peroxide aqueous solution, mixed with magnetic powder, indicates that the selected coolant can be effectively used in solar collectors at temperatures of $60^{\circ} \mathrm{C}$ from 1.5 to 3 years, without a substantial loss of properties, what is proved by the results of long-term storage (1,2,3,5 years);

3. The described method can be recommended as an express-analysis of the kinetics of various reactions for the substances with the predetermined thermal physical and thermodynamic properties (heat capacities and heat effects of reaction).

\section{References}

[1] M. Ye. Pozin, Hydrogen Peroxide and Other Peroxidates, Leningrad, (1952)

[2] B. A. Dolgoplosk, Ye. I. Tinyakova, Generation of Free Radicals and Their Reactions Moscow, (1982)

[3] G. A. Seryshev, Chemistry and Hydrogen Peroxide Technology Leningrad, (1984) 